\title{
MUNICIPALIZAÇÃO EM SÃO PAULO: NO PEITO E NA RAÇA
}

O presente trabalho consta de excertos dos pronunciamentos de 4 Secretários Municipais de Saúde na Mesa-Redonda "Para onde vai a nona?", promovida pelo Núcleo de Investigação em SILOS [Sistemas Locais de Saúde], do Instituto de Saúde da Secretaria de Estado da Saúde de São Paulo.

A mesa-redonda, realizada em setembro de 1992, um mês após a IX Conferência Nacional de Saúde (a "nona"), propunha-se a uma reflexão sobre os rumos da Reforma Sanitária Brasileira, em particular o processo de Municipalização da Saúde.

Os Secretários presentes representavam desde um pequeno município da Região Metropolitana, Embú-Guaçú (Justino Augusto dos Santos Anjo), até o maior município do país, São Paulo (Carlos Alberto Pletz Neder); além de um município médio do interior do Estado, Botucatu (Antonio Luiz Caldas Júnior) e outro grande, do Vale do Paraíba, São José dos Campos (Gilson de Carvalho). Coordenou a mesa-redonda, José da Rocha Carvalheiro, tendo dela participado, ainda, Otávio Azevedo Mercadante, então Superintendente Regional do INAMPS, em São Paulo.

A publicação do inteiro teor de todas as manifestações é de responsabilidade do Núcleo de Investigação em SILOS do Instituto de Saúde, que consentiu nas transcrições da parte dos pronunciamentos diretamente relacionada ao 
processo de municipalização*.

Este artigo insere-se no esforço do Comitê Editorial de "Saúde e Sociedade" no sentido de apresentar relatos de experiências concretas na construção do SUS [Sistema Único de Saúde].

\section{Dr. Caldas}

A $9^{a}$ Conferência Nacional de Saúde [CNS] foi um momento de síntese, porque as experiências de municipalização, de Sistemas Municipais de Saúde, precederam a $9^{a}$ CNS em muitos municípios, principalmente aqui no Estado de São Paulo. 0 movimento da municipalização, que se iniciou com as AlS [Ações Integradas de Saúde], no Estado de São Paulo com os "municípios carentes", teve na $8^{\text {a }}$ Conferência sustentação técnica, sustentação legal, e acabou se consolidando no SUDS [Sistema Unificado e Descentralizado de Saúde] quase como uma antecipação, já em 87, da Constituição. Arrumou-se uma fórmula, talvez limitada, capenga, de institucionalização desse processo que foi o convênio SUDS. Implementado, com acertos e com erros, no Estado de São Paulo, acho que significou um grande avanço no sentido da municipalização. Lamentavelmente, exatamente depois que a Constituição foi aprovada, esse processo começou a refluir por razões absolutamente de ordem politica e não por razões de ordem técnica. Primeiro, no final do Governo Sarney, houve mudanças por ministros que deliberadamente se opunham ao processo de construção do SUS. Segundo, outro principal obstáculo era exatamente a descentralização. Temos no Estado de São Paulo uma situação completamente esdrúxula na Capital, que até hoje passa à

* A transcrição dos debates foi realizada pelo Núcleo de Investigação em SILOS, com a revisão técnica de Luiza Sterman HEIMANN. 
margem do processo legal de Municipalização.

As razões de impedimento ao SUS no governo Sarney eram mais de ordem politica no embate entre o setor público e privado. No governo atual, o governo Collor, este embate tem uma dimensão maior ainda porque o desmonte das polfticas sociais passa a ser politica de Estado. Esta questão foi vista com grande dificuldade de entendimento desde o início do governo, não se conseguindo imaginar as dificuldades no avanço do SUS. Se é um problema da essência do governo, a polftica neo-liberal, é uma afronta deliberada à situação de saúde e de vida da população.

As pressões por um processo de construção do próprio SUS, fruto da organização popular existente na área da saúde, por mais limitada que ela seja e numa dimensão que não tem paralelo em nenhum outro setor, é uma possibilidade de enfrentamento a esta política. A constatação que se faz seja num grande município como é o do Gilson, seja num pequeno como é o do Justino, seja num médio município como é o meu, seguramente mostra um profundo retrocesso que não foi interrompido inclusive com as recentes mudanças ocorridas no ministério.

Acho que teríamos que discutir mais profundamente o que foi esse desvio policial do SUS, de roubos, de fraude e desmantelamento da CEME [Central de Medicamentos] pelo irmão do PC Farias, e qual é de fato a política do atual ministro em relação ao projeto neo-liberal na área da saúde. Sua posição, para quem o conhece, em relação à ética na politica, está clara. Mas na $9^{a}$ Conferência ele não poderia se prender à conjuntura, quer dizer, a uma rejeição ética ao governo, pois, com a mudança do presidente estará tudo resolvido? Não. Se mudar o presidente amanhã e se o ministro atual se mantiver, qual vai ser o rumo do SUS? Esta é a indagação que temos que fazer, qual é de fato a polftica a ser seguida porque, a nivel federal, ela ficou tão submetida a essa questão da imoralidade, da falta de ética, da 
corrupção, da roubalheira, que a população às vezes até desconhece qual é a política do atual governo.

Gostaria só de citar um fato que vivi no início do governo Collor: a ilusão de muitos setores progressistas que, num primeiro momento, ainda sob o impacto da crise do leste europeu e pela discussão que se estava fazendo a respeito do papel do Estado - os descaminhos do socialismo real nesse século inteiro - calcada numa análise, que era consenso, de mudanças na relação do Estado com os partidos, do Estado com a sociedade e do gigantismo do Estado nesses países, passaram a vir a público apoiando o discurso de desestatização levado por Collor. Isto é absolutamente reacionário, quer dizer, uma postura anti-estado, anti-politicas sociais e acabou sendo confundida como se realmente fosse um processo modernizador. Essa critica temos que fazer desse primeiro ano de Governo Collor, talvez dois anos, e vejo hoje a rediscussão desses aspectos, da privatização, como momento de rejeitar o neo-liberalismo. É evidente que temos crticas ao caráter do Estado brasileiro, como ele é, mas acho que de maneira nenhuma confundimos essa questão na $9^{\circ}$ Conferência.

Só queria, para terminar, colocar um aspecto que eu destaco como importante: a $8^{8}$ CNS foi riquíssima e como era uma conferência consensual em termos de diagnóstico e propostas eminentemente técnicas, digamos assim, permitiu o mesmo consenso de proposta no relatório final. Já a $9^{9}$ Conferência foi política e o diagnóstico foi também consensual, está escrito no relatório apesar de ter tido cem grupos trabalhando, com surpreendentes regularidades de posições, que ficaram resumidas na questão, cumpra-se a lei e fora Collor. Apesar do diagnóstico ter sido consensual acho que não poderia haver um consenso de propostas porque a Conferência Nacional de Saúde é atrelada ao Estado. Ela é convocada pelo Presidente da República e como foi uma Conferência eminentemente política, ficava difícil, com a diversidade de forças políticas lá presentes, tirar uma plataforma de 
ação. Era pedir demais para que a CUT, o PT, o PCdoB, a CONAM, a Igreja tivessem uma plataforma comum naquele momento. É por isso que vejo diferenças importantes entre os rumos da $8^{\mathrm{a}}$ e da $9^{\mathrm{a}}$ Conferências.

Os avanços do SUS, hoje, se dão muito mais por movimentos externos, como a definição dos partidos políticos a respeito desta questão, do que pelo desempenho dos técnicos, evidentemente, mas, com posições políticas que são dos partidos polfticos, das entidades de massa, da CUT, da CGT, da Força Sindical e assim por diante. Acho que era difícil se ter esse consenso numa reunião como a $9^{a}$ Conferência.

A experiência foi rica no primeiro momento, um momento de heroísmo, onde cada município procurou desenvolver seu sistema local. Botucatu começou a experiência de municipalização, não com esse nome, em 1983, logo após a eleição de 1982 e teve muita dificuldade, exatamente pela questão de recursos, pois não havia um fluxo de financiamento para essa experiência. Isso foi ganhando corpo com as Ações Integradas de Saúde e com a municipalização no Estado de São Paulo, em 87; o município experimentou um grande processo de expansão dos seus serviços. Pude acompanhar praticamente o que aconteceu no Estado inteiro e acho que foi uma experiência muito importante apesar de todos os erros, de eventual autoritarismo.

A municipalização ocorreu, e a responsabilidade foi transferida mas não ficou claro como se ia processar esse mecanismo de descentralização. A situação hoje é a que todos vão repetir aqui, quer dizer, o município assume a questão do financiamento da forma que consegue, ou fecha o serviço.

A maior perversão que se fez no início do governo atual foi ter transformado os parceiros do SUS, nos diferentes níveis de governo que a 
Constituição define, em prestadores de serviços e, colocado todos na mesma vala comum: hospitais universitários, hospitais públicos, com a falsa idéia que cada um deveria mostrar sua competência.

O público tem que concorrer com o privado, ser competente. Isso é uma aberração, é anticonstitucional, pois os municípios, quando transformados em prestadores de serviços, passam a ser tratados como qualquer outro prestador. É desrespeitado o que está escrito na Constituição de forma absolutamente clara - tem que haver transferência de recurso, tem que haver partição no dinheiro que é comum, que pertence aos municípios, aos Estados e ao Governo da União.

Os recursos que já são do município e do Estado, a União deve simplesmente repartir com critério. $O$ problema é descobrir que critério é esse. Colocar que a UCA [Unidade de Controle Ambulatorial] é um critério, se for para chutar, pelo menos vamos fazer um chute que tem a ver com o artigo 35 da regulamentação do SUS. Porque, qual é o critério da UCA? Se não é absolutamente um chute estar o valor alto, estar baixo, o que quer dizer isto? Não quer dizer nada.

A situação do financiamento, hoje, é uma política deliberada do Governo Federal para desmoralizar as políticas públicas, como bem falava o Magri, que por ser um sujeito mais ingênuo, talvez tenha confessado isso nos corredores do ministério: "A situação tem que ficar ruim mesmo para os aposentados para que quando propuserem a privatização da seguridade isso possa acontecer". Na saúde é a mesma política deliberada que aconteceu com os municípios. Na experiência de Botucatu, apesar disso, estamos num patamar centenas de vezes maior, melhor do que estávamos dez anos atrás, não tenho a menor dúvida, e não é só para Botucatu mas, para qualquer município do interior do Estado. Trabalhei na Secretaria de Estado de São Paulo, fui diretor de ERSA [Escritório Regional de Saúde], quer dizer, conheço muitas experiências a nível municipal e sou testemunha de que é inegável 
que houve mudanças antes e depois do processo de municipalização.

\section{Dr. Neder}

Queria começar considerando o aspecto mais geral em relação à $9^{a}$ Conferência e suas possibilidades de desdobramento. A gente tem que depositar uma esperança grande nesse potencial de luta da sociedade civil e dos movimentos sociais. Ocorre que me preocupa o fato de que essa é a única bandeira que restou nas mãos dos movimentos populares. $O$ fato de ser membro atuante desse movimento, no caso do Estado de São Paulo, conheço nominalmente as pessoas, as lideranças, sei do potencial desse movimento. Esse movimento jogou tudo na $8^{\mathrm{a}}$ Conferência, na vitória que nós tivemos na Constituição, numa correlação de forças totalmente desfavorável no congresso constituinte, e hoje se debate com as dificuldades que temos enfrentado para colocar em prática as resoluções que estão contidas na Constituição Federal e Lei Orgânica da Saúde. Portanto, esse não é um patrimônio inesgotável e precisamos medir exatamente qual é o nível de responsabilidade do setor público, dos órgãos, das instituições que hoje detém uma parcela de poder no sentido da implementação dessa proposta.

Até quando nós vamos poder contar com o aval e o empenho desse movimento que gradativamente começa a ser permeado por dúvidas sobre a viabilidade da proposta que apresentamos e que fizemos aprovar? Vem aí o Movimento da Reforma Constitucional de 93 e nós sabemos dos ataques que sofreremos. Estará confirmado que o SUS era devaneio das esquerdas numa conjuntura onde o setor privado não participou da $8^{\mathbf{a}}$ Conferência e não conseguiu, através dos seus lobbies, fazer vingar uma proposta mais factível? Nós teremos que enfrentar esta discussão em 93 mostrando que, na prática, o SUS não se viabilizou de acordo com toda a sua potencialidade em função da falta de vontade política e 
parcimônia entre os parceiros desse sistema, e não pela sua própria formulação, pela sua origem. Essa é uma preocupação que nós estamos tendo, e vem daí a avaliação que eu faço, que todo e qualquer avanço que se conseguiu nos municípios é patrimônio do movimento da reforma sanitária.

Portanto, acho no mínimo irresponsável, num período eleitoral como esse em que nos encontramos, que questões que são caras ao movimento social, ao movimento popular e a todos nós que nos incorporamos ao movimento da reforma sanitária, sejam de forma superficial, leviana e injusta, colocadas em questionamento. É uma questão que não é meramente de embate eleitoral para saber quem é que vai estar à frente da prefeitura no próximo período. Acho que a continuidade desse projeto de polftica sanitária é uma bandeira de todos nós independente da coloração partidária, da posição ideológica.

Podemos ter divergências inclusive sobre qual é o grau de afirmação do setor público, que adaptações ele deve sofrer para sua maior racionalização, porque isso também é uma bandeira nossa e não é exclusiva dos setores privativistas.

A $9^{a}$ Conferência não conseguiu discutir sequer minimamente a questão do contrato de gestão e outras alternativas. Nós temos experiências tremendamente ricas em vários municípios sob orientação de diferentes partidos, e quando há vontade política, quando se investe no setor saúde, quando se entende a questão da saúde não apenas como uma ação a ser desenvolvida numa única Secretaria, mas uma ação inter-secretarias, integrada, com envolvimento direto da organização popular, é perfeitamente possível inverter indicadores numa conjuntura desfavorável. Assim, damos alguma esperança para a população, para que ela possa avançar na sua organização, pois, ela precisa de exemplos concretos, precisa ver que estava correta quando saiu em defesa do SUS nas ruas e no Congresso Nacional. 
Infelizmente, tivemos condições muito adversas para fazer avançar o SUS na capital de São Paulo, se considerarmos que deveríamos ser parceiros atuando nos diferentes niveis de governo. Nesse sentido, nós não pudemos nos juntar para fazer um embate institucional, pois, a todo momento, sentimos que a discussão estava sendo feita de maneira superficial e injusta. Não podemos aceitar que, numa cidade como São Paulo, se apresente como solução para os problemas de saúde, ônibus itinerantes, unidades móveis de saúde com médicos, assistentes sociais e outros profissionais. Em São Paulo, sabidamente, faltam 100 unidades básicas de saúde, dimensionadas para atender $\mathbf{2 0 . 0 0 0}$ moradores cada uma. Temos um débito da ordem de 10.000 leitos hospitalares, sem considerar aqui a quantidade de leitos que são apresentados como existentes, mas que na prática são apenas planejados e não efetivamente abertos para disponibilidade da população. Não podemos aceitar propostas que têm sido apresentadas por candidatos à prefeitura que não tenham qualquer correspondência com a gravidade e com a complexidade de um programa de saúde para uma metrópole como São Paulo. Nós não podemos aceitar isso, dado o nosso compromisso profissional e a dignidade de cada um que está aqui representada nessa mesa. Este discurso é totalmente irresponsável na medida em que gera, para a população, uma expectativa de solução de curto prazo para um problema que não se resolverá na próxima década, mesmo que a gente implemente a proposta do SUS na sua totalidade no Município de São Paulo.

Nosso trabalho se iniciou numa Secretaria tradicionalmente voltada para assistência médica individual, para atendimento às emergências. Além de todos os investimentos na ampliação de hospitais, de pronto socorros, de leitos hospitalares da rede de atendimento pré-hospitalar, se buscou mudar o perfil da Secretaria através de ações de saúde coletiva com equipes multiprofissionais. Estas equipes foram constituídas através de concursos públicos para assistente social, psicólogo, nutricionista, educador, terapeuta ocupacional, etc, que é fundamental para poder 
diversificar a prática na Secretaria da Saúde, inclusive rompendo com a tradição de que apenas médico pode ser chefe de unidade de saúde. Na prática, hoje temos diversas categorias profissionais respondendo por unidades de saúde, com igual ou maior eficiência do que outros colegas médicos.

Temos, desde 89, um projeto de lei na Câmara Municipal que abre o provimento das chefias das unidades básicas para outras categorias de nível universitário, projeto este, que está sendo sistematicamente bloqueado. Este é um exemplo de questão, entre outras, em que nós deveríamos estar somando esforços com todas as legendas partidárias a partir do ideário do movimento da reforma sanitária.

Quando se fez a reforma da Secretaria Municipal de Saúde foram criadas 10 Administrações Regionais de Saúde - ARS - e 32 Distritos de Saúde na cidade de São Paulo, dos quais 14 são hoje unidades orçamentárias, mas vamos iniciar o ano de 1993 com 28 distritos de saúde sendo unidades orçamentárias. Apenas 4 não serão unidades orçamentárias por avaliarmos que nestes distritos, isto só teria sentido a partir do momento em que se concretizar a municipalização.

Com esta reforma administrativa, não apenas estamos fazendo uma divisão geográfica do poder, mas estamos dando condições para que o planejamento se faça a partir do nível local. Não é o gabinete do Secretário que faz a compra, não é o gabinete do Secretário que faz a política de suprimento, não é o gabinete do Secretário que sequer define as metas a serem cumpridas. Há uma única politica na Secretaria Municipal de Saúde, existem diretrizes, mas o planejamento se faz a partir do nível local e é fundamental que se faça com a participação dos trabalhadores e da população.

São 110 conselhos gestores que têm a participação tripartite: do 
governo, dos funcionários e dos moradores, fiscalizando e participando das decisões das unidades da Secretaria, seja a nível local, distrital, regional ou no Conselho Municipal de Saúde.

Teremos agora a III Conferência Municipal de Saúde que vai ser realizada nos dias 17 e 18/09, no Anhembi, onde esperamos ter de 3 a 4000 pessoas. Para este evento convidamos não só o Ministro da Saúde, como todos os candidatos à prefeitura do Município de São Paulo, para que possam ter a oportunidade de apresentar para a cidade quais são as plataformas para a área da saúde, como eles avaliam o trabalho que vem sendo feito, o que deve continuar e aquilo que merece restrição, mas, sobretudo, é necessário que se defenda um projeto de politica sanitária que não pertença exclusivamente a um único partido.

Neste sentido, gostaria de dizer que na questão da municipalização, como sabem, desde 1989 para cá, assumimos 20 unidades básicas (UBs), inclusive 0 pronto-socorro e ambulatório de especialidades de Sapopemba. Assumir 20 unidades de saúde sem financiamento significa muito mais do que a municipalização em muitas cidades do interior que receberam recursos.

Nós estamos, neste momento, concretizando uma negociação para assumirmos outras 30 unidades básicas, totalizando 50 unidades, que foram transferidas do Estado para o Município, desde 89, sem qualquer contrapartida financeira.

O que é que nós temos, fora o orçamento da Prefeitura de São Paulo para implantar o SUS na cidade, uma vez que não foi municipalizada? Foi recebido o pagamento por produção do governo federal, que representou, em 1991, 13,3\% do orçamento da Secretaria da Saúde, através das AlHs [Autorização de Internações Hospitalares] ou do convênio SUDS. 
Nós não recebemos qualquer tipo de pagamento por parte do Governo Estadual, em 1991, seja a título de custeio, seja a título de investimento, ou seja, a tftulo de recursos de capital. Acho importante que fique claro, para que não pareça uma panacéia, que não pensamos que o repasse de recursos do Governo Federal é suficiente para nós fazermos a municipalização na Cidade de São Paulo, na sua totalidade. Gostaria de precisar que existem 3 negociações de municipalização sendo feitas simultaneamente na Cidade de São Paulo. Nem sempre tenho a oportunidade de dizer isso.

A primeira proposta é a municipalização total que envolve 217 UBS, 17 hospitais gerais, 25 ambulatórios de especialidades e 25000 funcionários do Governo do Estado de São Paulo, incluindo os que foram estadualizados pelo INAMPS. A Prefeitura teria que assumir a equiparação salarial, porque hoje ela paga o dobro dos salários que são pagos aos funcionários estaduais. Além do que, há o reconhecimento, em documentos oficiais do próprio Governo do Estado de São Paulo, que esses 25000 funcionários representam hoje apenas $1 / 3$ do quadro de pessoal que as unidades estaduais deveriam ter.

Um dos impasses é que cerca de 40 a $50 \%$ dos funcionários já são funcionários municipais e indevidamente têm dois vínculos empregatícios. A partir do momento em que se faz a municipalização, o problema tem que ser resolvido porque passa a ser detectado. A partir do momento em que o funcionário vem para a prefeitura, sou obrigado a tomar uma providência, ou melhor, resolver o que é que se vai fazer. Se pretende continuar a ser funcionário do Estado, afastado para a Prefeitura e a Prefeitura pagando a equiparação salarial, ou se ele pretende optar pelo seu vínculo exclusivo na Prefeitura, com exceção do profissional médico que pode ter dois vínculos no setor público. Hoje, nós já pagamos equiparação salarial a cerca de 300 a 350 funcionários do Governo do Estado que estão na Prefeitura. Entretanto, a municipalização total significa fazer isso para 25000 funcionários sem contar os 
outros 2/3 que são cargos vagos que teriam que ser contratados pela Prefeitura, pagando seus próprios salários.

Conclusão: achamos que equacionar o problema da municipalização da Cidade de São Paulo na sua totalidade, exige necessariamente a participação de uma reunião, numa mesma mesa, do Ministro da Saúde, do Governador de Estado, da Prefeita Luiza Erundina e da sociedade civil porque, não é à toa, que a municipalização não avançou nas capitais e não avançou nas cidades de grande porte. E aí onde estão os serviços mais complexos, mais onerosos e que exigem um tratamento diferenciado.

Não é problema apenas da Cidade de São Paulo. Sabendo disso, há uma segunda negociação em curso, que consiste em fazermos com que a municipalização ocorra em pelo menos 30 unidades básicas que estavam fechadas até recentemente, que são do Programa Metropolitano de Saúde, mais o Hospital de Guaianazes e o Hospital de Parada de Taipas. Como essas unidades estão extremamente desfalcadas de pessoal, nós exigimos que haja uma cláusula financeira no termo da municipalização. Dessas 30 unidades, 24 foram colocadas recentemente em funcionamento, há 15 ou 20 dias mais ou menos, de forma extremamente precária, sem qualquer nível de resolutividade. É uma situação extremamente instável, e exige, portanto, um acordo do Governo do Estado e do Governo Municipal. Nesse acordo, nós podemos inclusive prescindir da participação do Governo Federal, dado que a municipalização é em escala muito menor.

A terceira proposta, que está em fase final de negociação, e que eu espero - bateria até aqui na mesa para ver se dá sorte - nós possamos assumí-la nos próximos dias, é um convênio geral da municipalização que, entretanto, tem apenas um primeiro termo aditivo através do qual nós regularizamos a situação das 20 unidades já recebidas pela Prefeitura de 89 para cá, além de receber outras 30 
unidades que são unidades do Governo do Estado - CS I, CS II e ambulatórios que já estão funcionando. Estes serviços seriam otimizados pela Prefeitura, através da contratação de profissionais de nível médio especializado, para transformá-los em ambulatórios de especialidades.

Não mencionei a questão da Vigilância Sanitária que é uma questão incompreensivel. Por ambas as partes, governo estadual e municipal, o discurso é de que há um comum acordo que se faça a municipalização da Vigilância Sanitária. Entretanto, na prática ela não acontece.

Em relação à Vigilância Epidemiológica, existem mais restrições à sua municipalização, mas nós a entendemos como extremamente necessária. Já conversei com especialistas a esse respeito, porque acho que é possível nós inovarmos a forma de fazer a Vigilância Epidemiológica no Município de São Paulo. É necessário repensar o papel do CVE [Centro de Vigilância Epidemiológica], a questão da presença do Ministério da Saúde nessa área, para que possamos fazer um Centro de Formação em Vigilância à Saúde com a participação do Governo Federal, do Governo Municipal de São Paulo e com a do Governo Estadual. Cada nivel de governo teria seu respectivo papel, mas caberia ao município o papel de gestor do sistema de Vigilância à Saúde no âmbito do Município.

Quanto à questão da saúde do trabalhador, nós abrimos 16 centros de referência no Município de São Paulo. O governo do Estado tem apenas um que é o Centro de Referência da Zona Norte. Por isso, é incompreensível para nós que não se tenha feito a municipalização desse Centro de Referência.

Estou citando alguns aspectos da municipalização, que são extremamente importantes, e que poderiam ser exemplos para que a população hoje tivesse pelo menos um grau maior de convicção de que o SUS não é um objeto não 
realizável, expressão apenas de uma vontade de setores esclarecidos da sociedade. Estou dando dados concretos e espero sinceramente que a gente feche esse acordo nos próximos dias.

Acho que os candidatos Suplicy [PT] e Aloysio [PMDB] deveriam ter pelo menos a sensibilidade polftica de sair a público nos próximos dias, e mostrar que os avanços obtidos na Cidade de São Paulo são patrimônio da esquerda, das forças progressistas, e tirar do Paulo Maluf [PDS], que nada fez pela saúde publica até hoje no Município de São Paulo, a bandeira que irresponsavelmente ele tenta carregar. De forma leviana, de forma pouco séria, ele apresenta propostas simplistas para o Município de São Paulo e quando faz seu programa na TV, como fez ontem à noite, mostra todas as unidades de saúde do PMDB que estão fechadas, que estão abandonadas, que estão depredadas, que foram invadidas e não falou nada. Simplesmente mostrou unidades que estão a um ano e meio fechadas, e que nós não conseguimos fazer com que o Governo do Estado as colocassem em funcionamento, em função do baixo salário que tem pago a seus funcionários ou que se acertasse a municipalização com a Prefeitura de São Paulo. Gostaria muito de ter feito o programa, apesar de entender que é falso o que foi dito porque ele não tem legitimidade para dizer o que diz. Esta deveria ser a nossa bandeira, e acho, portanto, para concluir, que nós deveríamos fazer a municipalização e não enganar a população. Mostrar que estamos apenas dando os passos iniciais da municipalização, que seria uma conquista do movimento sanitário na Cidade de São Paulo e não apenas de um partido.

Quero dizer que, enquanto não houver a parceria tão desejada, não me furtarei a usar do papel excepcional do posto que ocupo para polemizar, assumir o atrito, o confronto, sempre que achar necessário para defender essa política em que eu acredito. 


\section{Dr. Gilson}

Vou ficar com a fama de otimista por fazer um discurso diferente dos que aqui foram feitos. Quero enfatizar um tema que considero muito importante. No meio desse desespero, que nos assalta quando tocamos o dia-a-dia, meu discurso é otimista.

No meio de toda essa desesperança vi uma luz no fim do túnel. Acho que nós não conseguimos levar um discurso exclusivamente técnico, uma proposta técnica, só discutindo no meio técnico, mas, talvez tenhamos trazido a população muito mais para o nosso lado. A minha grande esperança hoje chama-se controle social. Estou apostando tudo no meu município, e em toda colaboração que eu possa dar em outros lugares, porque acho que é por aí, a sociedade tomando nas mãos a questão saúde, é que nós vamos buscar saídas e ter perspectivas.

Quanto à questão da municipalização, vou fazer de novo um depoimento otimista. Foi a única coisa nova que aconteceu no meio a essa confusão toda, no meio a esse desinteresse dos governos em cuidar da área da saúde. Onde se fez alguma coisa, onde se inovou, onde começaram a surgir coisas que o Governo Federal e o Governo Estadual não conseguiram implantar, foi exatamente nos municípios. Delinqüentemente, começamos a inovar em relação às chefias de unidade com enfermeiras podendo exercer esta função, em relação à equiparação salarial, isonomia com os estaduais, desde 1989, estes são alguns exemplos. Como se fez? Como se conseguiu? Como ficou a CLT? Como ficou isso? Não importa! O dinheiro naquela hora ia resolver o problema, o que vai acontecer depois... descubram outra solução: alguma lei de criação de cargos para alocar os funcionários municipalizados, etc. Estas delinqüências foram acontecendo com maior facilidade ou com a maior dificuldade. 
Lembro a questão das bandeiras da esquerda, colocadas pelo Neder. $\mathrm{O}$ bonito que aconteceu nos municípios, é que não teve mais bandeira de esquerda ou direita, foi um negócio supra partidário. Pergunto: por que houve dificuldades com os governos de esquerda que não conseguiram avançar muito na implantação do SUS ? Porque as idéias não são patrimônio de $A, B$ ou $C$ ou de $D$, elas podem ser universalmente aceitas, com maiores avanços onde houver maior facilidade de negociação. Então, com a municipalização, o que aconteceu de novo, foi dentro dos municípios.

Quanto à descentralização muita gente agora está fazendo caricatura, fala-se, por exemplo, em prefeiturização, quer dizer, o prefeito manda em tudo. Meu Deus do céu, se nós analisarmos exatamente os desmandos que podem acontecer nos municípios, eles sempre vão ter um aspecto muito menos maléfico do que qualquer desmando que possa acontecer em nível estadual e federal. Alguma falcatrua, uma corrupção de nível federal, corresponde ao orçamento total de 100 a 200 municípios. Agora, se o prefeito fez isso, fez aquilo, fez aquilo outro, colocou todos os filhos dele no Conselho, pegou o dinheiro todo da saúde e fez uma outra coisa - fez uma estátua, fez uma fonte luminosa na cidade - lá, no município nós podemos corrigir. Nós não estamos conseguindo fazer isto a nível federal nem a nivel estadual. Um exemplo é o Conselho Estadual de Saúde de São Paulo, um dos Estados mais importantes do País, que está com a seguinte proposta de composiçäo: 12 membros, sem representantes dos municípios e dos servidores. Nós, técnicos, não estávamos sabendo disso, não tínhamos recebido o Diário Oficial. Uma pessoa da população ligou para mim alertando para o prazo para fazer as emendas. Ou seja, a comunidade procurando discutir um interesse a que nós técnicos nem tínhamos tido acesso ainda pelo Diário Oficial. Quando o D.O. chegou ao nosso município, já tinha acabado o prazo de apresentar emendas ao Projeto infame, para dizer um nome bonito, do Governo do Estado, para o Conselho Estadual de Saúde. Inventou 
tudo o que podia: a lista tríplice para a comunidade escolher os seus representantes e outras coisas mais. Não estou endeusando o controle popular, o controle social, não estou endeusando a municipalização, pois, está cheia de defeitos, está cheia de nós crficos.

Podíamos discutir uma série de nós criticos que estamos enfrentando. Já situei a questão do financiamento e estou achando que o maior problema e sua solução passam pelos recursos humanos; é fundamental. Ou nós valorizamos os recursos humanos e podemos ter a cobrança em seguida, ou nós não valorizamos o essencial. Por que? Porque se faz sistemas de saúde com US $\$ 200$ per capita, como se faz sistemas de saúde com US $\$ 2500$ per capita. Quer dizer, o financiamento pode não ser o essencial se não tivermos uma discussão com todos os envolvidos na proposta.

Tenho discutido o modelo assistencial. Não é possível, num país com US \$ 2160 per capita de renda, fazer o que nós estamos chamando hoje de americanização perversa da saúde. Você importa o modelo, impõe à população consumo de especialista, consumo de remédios, consumo de equipamentos, e vamos depender disso. Nós só vamos modificar esta situação com a participação da comunidade, e discutindo com os técnicos. Temos que fazer um grande investimento nos recursos humanos, isto é, o preparo dos trabalhadores, a valorização do trabalho, a valorização dos salários dos profissionais.

Então, esses nós crfticos que nós temos na municipalização passam pela discussão do modelo, passam pela discussão do próprio controle social, para que ele seja efetivo, e não haja simplesmente um atrelamento da comunidade para poder apoiar as nossas coisas.

Eu sofri com o Conselho de Saúde. Quando nós assumimos tinha havido 
desvio de dinheiro na administração anterior. Então, tinha um Conselho de Saúde me pressionando, dizendo "esse vai fazer a mesma coisa", "só tem pinta de bonzinho". Foi um ano de briga, de desconfiança, até você chegar e conseguir fazer realmente ver que o administrador entende a importância da transparência. Assim, o Conselho assume determinadas posições, ele vai à frente.

Estamos fazendo um curso de formação para esse pessoal. Quer dizer, é o grande investimento que a gente tem. Para cada nó critico você vai ver que algum município já descobriu uma resposta e está experimentando essa resposta, às vezes delinqüentemente para tentar sair do buraco, para tentar resolver o problema. $E$, na hora em que você coloca 5000 municípios juntos para discutir, que é o número de municípios brasileiros, vai ter um punhado de gente bolando e tendo autonomia para descobrir respostas para os problemas. Você vai ter muito mais chances de acertar do que através de resoluções feitas em gabinete que tem cinco, seis técnicos.

É lógico, evidente, que a metade dos brasileiros vive com menos de um salário mínimo - sobrevive - então, estas descobertas, na hora em que se aposta na criatividade das pessoas, na autonomia e no fortalecimento do poder local, acho que há saída.

Estamos defendendo a municipalização como um princípio da descentralização, como fazendo parte do povo, inserida numa proposta mundial que é o fortalecimento do poder local. Quem está mais perto é mais controlável. Quem está mais perto dá uma resposta mais ágil, mais pronta às necessidades da população.

Tenho milhares de problemas com a municipalização em São José dos Campos, com diagnóstico e tudo, e a gente está tentando descobrir soluções. É preciso apontar alguns caminhos que devem ser valorizados, não na euforia, mas, 
com conseqüência. Está tudo bom? Absolutamente! Sei que tudo está ruim mas eu estou vendo uma luz no caminho.

O financiamento federal caiu enormemente, foi para desmontar o sistema público e já estou com saudade do SUDS. Será que o SUDS avançou mais do que o SUS justamente porque ele era delinqüente, ele era paralelo, e ninguém dava muita importância? Na hora em que nós conseguimos colocar na lei, o pessoal disse: espera al, o negócio é sério, agora está na lei e agora nós estamos emperrados. Será que é só falta de vontade polftica de fazer as coisas acontecerem? O maior drama que nós vamos ter é transferência de dinheiro. Na hora em que se transferir dinheiro para nivel local, vocês vão ver que a gente vai arrebentar esse país, dando respostas melhores, perdendo muito menos dinheiro. Nós conseguiremos fazer concorrências com controle, com a comunidade olhando licitação, conseguindo concorrência com $50 \%$ de diferença de preço com as concorrências anteriores, vocês acreditem nisso! Quer dizer, é possível a gente conseguir negociar. Nesse sistema de licitação pública, que é legal mas não é moral, de repente pode ser feito alguma coisa diferente como nós fizemos, por exemplo: compramos, colocamos o dinheiro no bolso e fomos atrás, pechinchamos, buscamos o que é melhor, o que é mais barato. Nós só estamos podendo inovar lá em baixo com o controle das pessoas, então estou apostando nisso.

Estamos desde 76 no projeto de municipalização de São José dos Campos. Temos 2.000 funcionários, 45 unidades entre grandes, médias e pequenas, especializadas, gerais etc. e a gente tem uma série de problemas mas, no meio dessa série de problemas, estamos conseguindo avançar.

Recebi 50.000 desempregados dentro do sistema público que tinham algum tipo de convênio; recebi a recessão em São José dos Campos, que começou antes da recessão do Brasil, quando diminui a venda de armamentos e produtos 
bélicos. Um pessoal altamente especializado em produção de armamentos que não tinha outro mercado de trabalho, o pessoal de classe média e às vezes de classe média alta passou a usar o sistema público, que não implodiu ainda.

Conseguimos sobreviver no meio de inúmeras dificuldades, o que foi uma resposta. Enquanto fizemos isso, nos últimos 30 anos, continuou o mesmo PAM do INAMPS, o Estado continuou com o mesmo Centro de Saúde que tinha, quer dizer, quem fez alguma coisa foi o município. Hoje, do gasto com saúde, $80 \%$ é municipal, o Estado continua entrando com praticamente nada, e a União entra com $20 \%$ do dinheiro.

\section{Dr. Justino}

Eu queria tratar inicialmente da questão do resgate do conceito de cidadão. Acho que saúde, na realidade, é um conceito amplo e fico olhando a atividade médica, médicos que atendem o paciente. Você o trata hoje, daqui a dois meses ele volta com o mesmo problema, quer dizer, se a gente não interferir nas outras coisas, não só na questão da assistência, nós vamos ficar como um saco sem fundo.

Acho que nós, na realidade, devemos ampliar esse processo de discussão. Será que nós estamos garantindo o direito do cidadão, inclusive o dos nossos funcionários?

Diante disso, eu vou me pautar um pouco mais na experiência de EmbúGuaçú. Uma das primeiras coisas que a gente pensou, foi num projeto de formação de recursos humanos. Montamos uma escola de formação de auxiliar de enfermagem e aí nós nos deparamos com um segundo problema: os nossos funcionários não tinham escolaridade para freqüentar a nossa escola de auxiliar de enfermagem. Cria- 
se, então, um supletivo que é bancado pela Prefeitura. Os objetivos eram: melhorar a qualidade do serviço, melhorar a questão financeira do indivíduo, atuar para que esse Recurso Humano assuma o trabalho com dignidade.

Eu atuo numa região já há dez anos, na região de Itapecerica da Serra. São basicamente 5 municípios onde ampliamos de 83 para 92, de 5 unidades de saúde para mais ou menos 80 unidades, todas municipalizadas. As cidades são tipicamente dormitórios, têm hum milhão de habitantes, não têm hospital, nossa referência secundária e terciária é o Hospital das Clínicas de São Paulo. Para se ter uma idéia, ambulatório de especialidade nós não temos. Nós utilizamos os ambulatórios de especialidades do SUDS-Regional 08 [SUDS-R8] e da região de Pinheiros. Essa é a realidade.

Ampliou-se a assistência primária. Temos lá na nossa região um hospital que foi conseguido na legislatura municipal anterior - 82/88 - através da luta da população e esforços dos governos locais, e que se encontra atualmente parado.

Como nós hoje conseguimos resolver a questão do financiamento? 0 financiamento é importante para nós porque o que caracteriza uma cidade dormitório é basicamente sua arrecadação, o IPTU, e o repasse do Fundo de Participação dos Municípios. Com uma arrecadação pequena, no nosso município bancamos a saúde nos últimos três anos e pouco.

Chegamos a uma realidade de aplicar $35 \%$ do arrecadado mensal na saúde. Sendo que, até então, antes de surgir essa nova modalidade de financiamento do INAMPS, nós tínhamos mais ou menos uma aplicação de 10 a 12\% de recursos municipais. Com a falta do recurso do Governo do Estado, a partir do governo Fleury, o Município passou a entrar com $35 \%$ dos recursos e isso estrangula o Município. Você passa, então, a contar com a disposição política do Prefeito. 
O que estamos assistindo ultimamente é um sucateamento total da nossa rede. Em município onde a gente criou uma estrutura, uma expectativa, por exemplo, Embú-Guaçú, o Prefeito vai bancar até o final, mas a gente não sabe no futuro; quer dizer, você constitui um sistema mas vive diante da incerteza.

Diante disso, neste ano começamos a batalhar: fomos ao Governo do Estado e ele fala o seguinte "custeio não é com a gente é com o Governo Federal", fomos ao Governo Federal e nos disseram: "parte do custeio é nosso, parte é do Estado então, o financiamento, não é nosso! O financiamento é do Governo do Estado!" Temos um hospital parado na nossa região porque depende do financiamento do Estado. Ou esse financiamento é do Governo Federal?

Você fica como um joguete nesse processo e fica aí rodando as esferas estaduais e federais sem ter uma definição concreta para onde ir, aonde você obtém algo para solucionar o seu problema.

Nós temos hoje uma maternidade com aproximadamente 20 leitos equipados, mas não podemos funcionar porque não temos recursos para dar um pontapé inicial. Temos situações do seguinte tipo: a gente investiu pesado na área de Odonto, por exemplo, e baixamos a incidência da cárie dentária com bochechos, escovação supervisionada, etc..

Nós, dos pequenos municípios da região metropolitana, estamos num mato sem cachorro ou num mato sem saída, ainda mais que a gente tem uma camisa de força que é a Lei da Proteção dos Mananciais.

As perspectivas que se tem diante disso, para a gente como dirigente municipal, é a assunção de que saúde é prioritária, e a gente vai lutar para isso, e isso vai ter um custo para esse prefeito porque ele não vai poder fazer obras públicas uma vez que $35 \%$ dos recursos irão para a saúde, $25 \%$ para a educação e o restante que 
sobra vai para a folha de pagamento do pessoal. Então você tem aí uma amarração: o financiamento do INAMPS privilegia o que? Grandes prestadores e grandes procedimentos.

Em Embú Guaçu, nós conseguimos reduzir a mortalidade infantil que estava em torno de 33 por 1.000; baixamos para 13. Reduzimos a mortalidade por diarréia, reduzimos por pneumonia, mas sacrificando todo o orçamento municipal e não sobra dinheiro para você atuar nos outros problemas. Os municípios são assim: tem $60 \%$ da população abastecida por rede de água, $0 \%$ de esgoto, então os grandes problemas precisam de investimentos externos para serem solucionados, porque o orçamento municipal está comprometido só no gerenciamento dessa máquina e você não tem nenhum alento diante disso. Essa região em que a gente vive, eu vivo, moro lá, está diante de um impasse.

Retomando a questão da cidadania, um meio é fortalecer os movimentos populares, porque, nessa região as Sociedades Amigos de Bairros, por exemplo, são criadas com caráter eleitoreiro exclusivamente. Por ser cidade dormitório, não aglutina. É fundamental discutir a questão da saúde, discutir os problemas, e a gente não tem outra alternativa a não ser investir no controle social, na participação da população. Um movimento popular com que cidadãos?. A população lá é $60 \%$ analfabeta, $70 \%$ declarados sem rendimentos, onde para uma cidade com 90.000 habitantes conta com duas escolas de ensino secundário, não tem uma faculdade na região, não tem ensino profissionalizante é, como chamo, uma população marginalizada.

Estamos diante de uma situação em que as pessoas não têm o que comer. É uma realidade a pior possível, quer dizer, estamos diante de um genocídio, um genocídio brasileiro, ou seja estão matando gente adoidado. Fico pensando em qual é o sentido de se fazer Assistência Médica, produzir uma média de 6 consultas 
habitante/ano só para tratar de gente que está pondo bicha pela boca, pelo nariz e bolo de áscaris, que é a coisa mais comum.

Nós, pequenos municípios da região metropolitana estamos diante dessa situação e isso significa mais investimentos em saúde, saneamento, investimento em lixo. São municípios, onde a coleta de lixo é precaríssima e não tem solução, porque é proibido fazer reciclagem de lixo devido à Lei de Proteção dos Mananciais.

Você quer colocar uma empresa não poluente para gerar empregos, the exigem o seguinte: a compra de $40.000 \mathrm{~m}^{2}$ para implantar uma indústria de $8000 \mathrm{~m}^{2}$, isto é, cinco vezes sua área. Não há flexibilidade. Nós mesmos para construirmos o hospital desapropriamos $46.000 \mathrm{~m}^{2}$ e, aí a gente se depara com outra coisa: tem que se proteger o verde, não se pode desmatar.

Por outro lado, o ilegal cresce adoidado: o loteador clandestino joga para dentro da cidade um monte de gente a cada ano, que está migrando da grande cidade para lá e se amontoando nos terrenos da prefeitura e em todo espaço vazio: em beiras de córregos, no que existe, enfim.

Assim é a realidade que a gente trabalha no dia-a-dia; e o Governo do Estado, desde que entrou esse atual Secretário, não tem repassado recursos. No ano passado se ganhou US $\$ 266.000$, atualmente, até agosto, tínhamos recebido US $\$ 24000$ do Governo do Estado, quer dizer, nem 10\%. Como é que a gente sobrevive ou faz serviços desse jeito, com uma política de Governo Federal que privilegia o pagamento a grandes procedimentos, e nós estamos fora disso?

Não temos maternidade de alto risco, não temos nada na região, só temos Unidades Básicas. Na região tem-se alguns municípios com bom trabalho, com pessoas que estão lá e que vestiram a camisa, gente que se juntou, se aglutinou, 
tudo num Município só e está fazendo um trabalho decente. De resto, é simplesmente medicalização. À medida em que você desmedicaliza a população, o faturamento é menor. Você implanta o programa na rede, controla o asmático, e o asmático de controle é considerado consulta simples, mas o medicamento que você fornece para ele, para ele estar controlado, é caro. Então hoje, temos só uma rede de serviços que passou para o município e a população está nessa miséria de que lhes falei.

Tem-se que ocupar um espaço e gritar, e aqui eu ocupei um espaço para caracterizar essa região. Falo um pouco mole, não dou muita ênfase, mas acho que é essa a realidade mesmo, e que de tanto você ver nem grita mais. Acho, mesmo assim, que merece que a gente dê um grito, que a gente deveria filmar todas essas coisas para trazer para as pessoas sentirem, porque só se sente vendo, falando muitas vezes a gente não sente a realidade. Obrigado. 